\section{Physiological Data Acquisition and Analysis with Your PC}

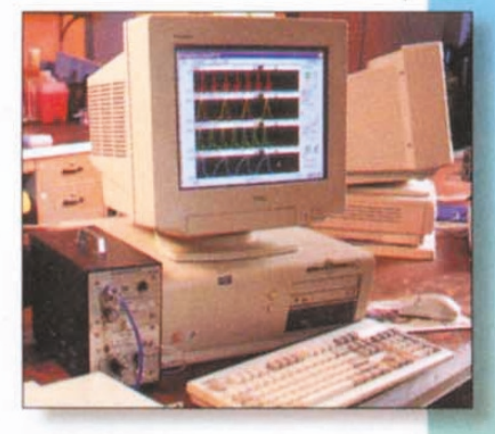

\section{BioBench $^{\text {TM }}$}

\section{empowers you to...}

use your current monitoring devices and amplifiers to acquire data specific to life science applications. BioBench implements PC based data acquisition for physiological monitoring and analysis.

- Turnkey application - No programming required

- Compatible with instruments and amplifiers providing analog voltage output

- Portable laptop solutions available

Call today for a FREE BioBench brochure (800) 661-6063
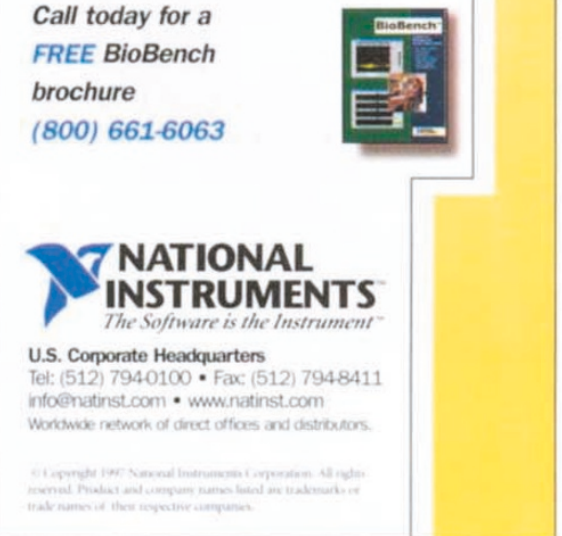

\title{
Industry critical of EC ethics survey
}

Contrary to popular consumer belief, a survey funded by the European Commission (Brussels) and published in March by the Dutch organization for applied scientific research (TNO; Apeldoom, Netherlands), reports that companies are very aware of ethical issues and consider them important. However, biotechnology industry organizations have been critical of the report, entitled "The Moral Competitiveness of Biotech Companies," suggesting it merely adds to the confusion in an already murky area.

The survey, compiled from interviews in summer 1997 with representatives of companies in Europe that use biotechnology, questioned attitudes toward ethics and biotechnology. "In the [general, public] debate about ethical aspects of biotechnology, attention has focused mainly on ethical thinking in society from the perspective of public acceptance of biotechnology. In our study we focused on how companies think and act in relation to the ethical aspects of biotechnology--the moral agenda of biotech companies," explains Christien Enzing, one of the researchers commissioned to do the study, at the TNO Institute for Strategy, Technology, and Policy in Apeldoorn (The Netherlands).

However, Erik Thambuyzer, responsible for corporate affairs at Genzyme, is critical of the EC-funded study. "We thought that a lot of the questions were misleading," he says, explaining that the questions were not specific enough to clearly separate individual beliefs from those of a company. He concludes, "The study was simply not scientific enough and might add to the confusion that everybody wants to avoid."

The survey was not as representative as one might hope-only two-thirds of the selected 15 companies were willing to participate (Schering [Berlin], Roche [Basel], Dompé Biotech [Milan], Novartis [Basel], Avebe [Veemdarn, Netherlands], Novo Nordisk [Bagsvaerd, Denmark], Tecnogen [Verna, Italy], Limagrain [Paris], Nutricia [Zoetemeer, Netherlands], and Genzyme [Leuven, Belgium]). Although the majority of these are not biotechnology companies per se, each is active in the fields of pharmaceuticals, agriculture-food, or both. (Companies unwilling to participate cited the time-consuming nature of the project and unformed ethical policies as excuses.)

"We were surprised that these companies actually devoted a lot of thought to this issue," says Enzing. "One company did have an ethical audit and another one had an ethical advisory

Ellen Peerenboom is a freelance writer working in Cologne, Germany. board. Others would ask professionals in certain cases for advice." An unnamed company explained that in the early 1990s it consulted external ethics experts to discuss ethics concerning the future development of gene therapy. As a result, the company decided it was not ethical to undertake research on germ cells.

Although the survey indicates company awareness of consumer concerns regarding ethics, only 3 out of the 10 participating companies reported regular contact with consumer groups-two with environmental groups, and one with paneis of laypeople. According to Enzing, almost two-thirds of the companies questioned think it important to notify consumers if a product is made using biotechnology. But she points out that, in contrast to the food industry, biotechnology is more accepted in medicine, and its use is not a major issue for pharmaceutical companies. In addition, Tambuyzer says that medical companies are obliged by law to provide information about drugs and test kits to doctors, not directly to patients.

The research project team that conducted the survey also concludes that the companies questioned desire a consumer dialog but are unable to engineer one because of the innate mistrust consumers have of companies. This problem cannot be solved simply by providing more product information, says Enzing. She suggests companies should publish their ethical standards so that there is an incentive to comply with them. "Companies that decide not to inform the public about their ethical values may risk criticism later on," says the report. The team recommends that intermediate organizations (such as the pan-European industry body, EuropaBio [Brussels]) or national biotechnology industry organizations (such as NIABA Dutch National bioindustry group [Leidschendam, Netherlands]) or Deutschen Industrievereinigung Biotechnologie [Frankfurt]) should invite consumerinterest groups or other interested parties to actively participate in discussions about ethical aspects of biotechnology.

EuropaBio already introduced a draft of its core ethical values in June 1997 (www.europabio.be/publications/pg001.htm). "We have appointed an external group of professionals of the field of ethics, which is advising us on the issue," says Tambuyzer, who is also EuropaBio's chair of the task force on ethics. He notes that the results will be announced at the next EuropaBio Meeting in October in Brussels. "We should and do participate together with academia and government in the public debate," says Tambuyzer, but stresses that EuropaBio currently lacks the resources necessary to be more active.

Ellen Peerenboom 